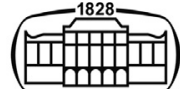

AKADÉMIAI KIADÓ

Acta Veterinaria

Hungarica

DOl:

$10.1556 / 004.2020 .00006$

(c) 2020 Akadémiai Kiadó, Budapest

\title{
Haematological and biochemical reference intervals in healthy racing and retired Italian Greyhounds
}

\author{
PAOLA SCARPA ${ }^{1,2}$ (D), BEATRICE RUGGERONE ${ }^{1,2^{*}}$ (1), \\ SARA GIRONI ${ }^{1}$, TIZIANA VITIELLO ${ }^{1,2}$ and \\ SAVERIO PALTRINIERI ${ }^{1,2}$ (1)
}

\author{
${ }^{1}$ Department of Veterinary Medicine, University of Milan, Via Celoria 10, 20133, Milan, Italy \\ ${ }^{2}$ Veterinary Teaching Hospital, University of Milan, Via dell’Università 6, 26900, Lodi, Italy
}

Received: July 26, 2019 • Accepted: January 10, 2020

\section{ORIGINAL ARTICLE}

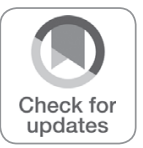

This work has been previously presented as a preliminary abstract at the 23rd ECVIM-A Congress in Seville (2011).

Present address: 0spedale Veterinario I Portoni Rossi, Via Roma, 57, 40069 Zola Predosa (B0), Italy. Phone: +39051 755233

${ }^{*}$ Corresponding author. Department of Veterinary Medicine, University of Milan, Via Celoria 10, 20133, Milan, Italy.

Phone: +39051 755233

E-mail: beatrice.ruggerone@gmail. com

\begin{abstract}
In view of the enormous variability of dog breeds, breed-specific reference intervals (RIs) are recommended for use in veterinary clinical decision-making. The aim of this study was to determine whether RIs of the general canine population may be applied to the Italian Greyhound (Piccoli Levrieri Italiani or PLI), and to generate breed-specific RIs, where appropriate. Sixty-three privately owned clinically healthy fasted dogs were examined. Routine haematology and biochemistry were performed on 58 enrolled patients using the ADVIA 120 haematology analyzer and the Cobas Mira system, respectively. Changes in haematological and biochemical parameters depending on sex, age and attitude (resting vs. running dogs) were investigated. The results of PLI were compared with the RIs of the general canine population. In those cases in which these RIs were not validated, new RIs were generated according to the guidelines of the American Society of Veterinary Clinical Pathology. Pre-existing RIs were considered valid based on the recommendations by the Clinical \& Laboratory Standards Institute (CLSI). RIs were higher for mean corpuscular haemoglobin (MCH), mean cell haemoglobin concentration (MCHC), cell haemoglobin concentration mean (CHCM) and lower for large unstained cells (LUC). A wider discrepancy between pre-existing and newly established RIs was found for some ADVIA parameters regarding red blood cell (RBC) or reticulocyte morphology. For total protein and cholesterol the new RIs were wider than the pre-existing ones, while albumin, calcium and iron were higher. This study suggests that most of the RIs published in veterinary textbooks cannot be validated for PLIs.
\end{abstract}

\section{KEYWORDS}

breed, clinical chemistry, dog, haematology, sighthound

\section{INTRODUCTION}

In people, reference intervals (RIs) are sought for specific subpopulations identified by sex, age, ethnicity and geographic origin (Horn and Pesce, 2002). In veterinary medicine, this approach is often ignored, but the availability of valid RIs is essential for the correct assessment of a patient's clinical status, and only a few studies have defined breed-specific RIs (Nielsen et al., 2010; Paltrinieri et al., 2014; Ruggerone et al., 2018).

In Greyhounds having several breed peculiarities, breed-specific RIs have been established (Campora et al., 2011a). Some of these peculiarities are shared by Lurchers, a crossbreed between a sighthound and other dog breeds, suggesting that genetics could play a role (Campora et al., 2011b). However, no information is available about possible breed-associated peculiarities of the Italian Greyhound (Piccoli Levrieri Italiani or PLI), belonging to group 10 (Sighthounds) of the Fédération Cynologique Internationale. Furthermore, in 
recent years the popularity of this breed has been growing not only in Europe but also in North America, with an increase in numbers all over the world. There is a growing interest in this breed and its peculiarities, which stimulates research including genetic studies. In order to avoid misdiagnosis due to the insufficient knowledge of haematological variables, the aim of this study was to generate RIs in healthy adult PLI, highlighting any differences according to sex, age and aptitude.

\section{MATERIALS AND METHODS}

\section{Selection of cases and samplings}

This was a prospective study on privately owned animals sampled with the owner's informed consent during plans of health monitoring (opinion of the Institutional IACUC n. 2/ 16 ; 15.02.16).

Samples were collected from healthy PLI belonging to 28 different breeders, according to the Clinical \& Laboratory Standards Institute (CLSI) recommendations (CLSI, 2010). The study included only dogs that fulfilled the following criteria: (1) No recent history of diseases or of pathophysiological conditions affecting blood results (pregnancy, lactation, tumours, infections, etc.); (2) Regular deworming and vaccination; (3) No recent medications administered; (4) No clinical signs at the physical examination. Samples with lipaemia, haemolysis, or icterus were excluded from the study.

Blood was collected at rest at least 7 days from a race in non-retired dogs, to avoid the effects of short exercise on blood parameters (Ilkiw et al., 1989; Horvath et al., 2014) from animals fasted at least for $12 \mathrm{~h}$, and transferred to the laboratory at $4{ }^{\circ} \mathrm{C}$ within $18 \mathrm{~h}$. Samples were collected within plans of health monitoring with the owners' informed consent. Therefore, according to the regulations of our Institution (Decision 2/2016 of the Institutional Ethical Committee) a formal approval of the Institutional Ethical Committee was not necessary.

\section{Laboratory analyses}

Haematology was performed using the laser-based ADVIA 120 haematology system (Siemens Healthcare Global, Erlangen, Germany), calibrated using calibrators provided by the manufacturer and checked weekly with quality control material. The haematological parameters, reported in Table 1, were recorded.

Leukocyte differentials were verified by microscopic examination of May-Grünwald-Giemsa stained smears by two independent operators: manual differentials were included in this study if positive flags regarding WBC counts were generated by the instrument, if $>1 \%$ of basophil, band neutrophils, or grey eosinophils (i.e. eosinophils with abnormal staining features, typical of sighthounds, that may be misclassified by automated cell counters as demonstrated by Giori et al., 2011) were microscopically detected or if the difference between the automated and the manual neutrophil or lymphocyte counts exceeded $\pm 5 \%$.

The biochemical analytes, reported in Table 1 , were measured in a single batch on an automated spectrophotometer (Cobas Mira, Roche, Basel, Switzerland), checked daily with two levels of quality control material (normal and pathological) provided by Giesse Diagnostics (RM, Italy) and calibrated using calibrators provided by the same manufacturer, based on the results of the daily quality control as necessary. Samples were processed within one month of sampling using serum obtained by the centrifugation $(1800 \mathrm{~g}, 10 \mathrm{~min})$ of blood collected in plain tubes, and frozen at $-20{ }^{\circ} \mathrm{C}$. Sodium and potassium were determined using a flame photometer (IL 943, Instrumentation Laboratories, Boston, US).

\section{Comparison with pre-existing canine Rls}

For each analyte, the results obtained were compared with pre-existing canine RIs (Moritz et al., 2004; Kaneko et al., 2008; Rizzi et al., 2010) using a specific software (Analyse-it, v.2.21, Analyse-it Software Ltd, Leeds, UK) according to the CLSI guidelines (CLSI C28-A3) as follows:

- Outliers (values exceeding the I or III quartile minus or plus $3 \times$ the interquartile intervals) were removed from the dataset;

- Twenty randomly selected observations were compared with the pre-existing RI:

o pre-existing RIs were validated if $\leq 10 \%$ of results ( 2 cases) were outside the pre-existing RI;

o pre-existing RI were rejected if $\geq 25 \%$ of results ( 5 cases) were outside the pre-existing RI;

o when results outside the pre-existing RIs were $>10 \%$ but $<25 \%$, additional 20 values were randomly selected and compared with pre-existing RIs; the pre-existing RIs were validated if $<10 \%$ of results were outside the interval and rejected if $>10 \%$ of results were outside the pre-existing RI.

\section{Establishment of new breed-specific Rls}

When pre-existing RIs were rejected, new breed-specific RIs were generated using an Excel spreadsheet with the Reference Value Advisor (version 2.0) set of macroinstructions (Geffré et al., 2011) that performs computations following the IFCC-CLSI recommendations as suggested by the ASVCP guidelines (Friedrichs et al., 2012)' The computations included: common descriptive statistic, test of normality, Q-Q plots and Box-Cox transformation. To detect outliers, Dixon-Reed and Tukey's tests were used. Following the ASVCP guidelines, outliers classified as 'suspected' by the software were retained while far outliers were removed from the analysis. The software calculates the RIs using five statistical methods (standard and robust methods on both non-transformed and transformed data and a nonparametric method) and indicates which of the five RIs should be used based on actual data distribution. A nonparametric bootstrap method was used to calculate the 
90\% confidence interval (CI) for the RIs. Due to the small sample size, differences were considered statistically significant if $P<0.2$.

\section{Partitioning of Rls}

The Wilcoxon and Kruskall-Wallis tests followed by the Tukey's test for multiple comparison were used to assess the differences related to sex, age ( $0-2$ years, $2-7$ years, $>7$ years), and aptitude (retired vs. racing dogs). Age was entertained also as a continuous variable using a linear regression analysis (JMP 7, SAS Institute Inc., Cary, NC, US).

\section{RESULTS}

Sixty-three dogs were sampled. Five dogs were excluded due to mammary neoplasms (two dogs), neurological signs of unknown origin one month before sampling, severe periodontitis and lactation (one dog each). Consequently, 58 dogs were included in the study. In 6 cases serum samples were inadequate for biochemical analyses. In all the dogs the automated differential counts were used, except in two cases that had $>1 \%$ of grey eosinophils.

Outliers were not common (Table 1). Pre-existing RIs were rejected for 18/34 haematological and 5/16 biochemical analytes. The new RIs of these analytes are reported in Table 2.

In most cases, the new RIs largely overlapped with the pre-existing ones (e.g. Hb, WBC, reticulocyte number, $\mathrm{MPV}$ ). In a few cases new RIs were higher (e.g. $\mathrm{MCH}$, $\mathrm{MCHC}, \mathrm{CHCM}$, albumin, calcium and iron) or lower (LUC) than the pre-existing RIs. A wider discrepancy between preexisting and new RIs was found for ADVIA parameters regarding $\mathrm{RBC}$ or reticulocytes. The new RIs of total protein and cholesterol were wider than the pre-existing ones.

Table 1. Number of samples included in the study: adequate samples, outliers removed (analytes that did not have outliers are not included in this table)

\begin{tabular}{|c|c|c|c|}
\hline $\begin{array}{l}\text { Adequate } \\
\text { samples }\end{array}$ & Parameter & Outliers & $\begin{array}{l}\text { Samples } \\
\text { included } \\
\text { in the study }\end{array}$ \\
\hline \multirow[t]{7}{*}{58} & $\begin{array}{l}\text { Red blood cells (RBCs), Haemoglobin (HGB), Haematocrit (HCT), Mean } \\
\text { corpuscular volume (MCV), Mean corpuscular haemoglobin (MCH), Mean cell } \\
\text { haemoglobin concentration (MCHC), Haemoglobin content (CH), Percentage of } \\
\text { macrocytic RBCs (\%MACRO), Total leukocytes (WBC), platelets (PLT), Mean } \\
\text { platelet volume (MPV), Platelet distribution width (PDW), Mean platelet content } \\
\text { (MPC), Haemoglobin content of reticulocytes (CHr), CH distribution width of } \\
\text { reticulocytes (CHDWr), Percentage of macrocytic reticulocytes (\%MACROr), } \\
\text { Percentage of reticulocytes with High CH (\%HIGH CHr), Percentage of low } \\
\text { fluorescence reticulocytes (L Retic \%), Number of low fluorescence reticulocytes } \\
\text { (L Retic \#), Percentage of medium fluorescence reticulocytes (M Retic \%), } \\
\text { Percentage of high fluorescence reticulocytes (H Retic \%), Number of high } \\
\text { fluorescence reticulocytes (H Retic \#), Immature reticulocyte fraction with high } \\
\text { fluorescence (IRF-H), Immature reticulocyte fraction with medium/high } \\
\text { fluorescence (IRF M+H) }\end{array}$ & 0 & 58 \\
\hline & $\begin{array}{l}\text { RBC distribution width (RDW), Neutrophils, Lymphocytes, Monocytes, Basophils, } \\
\text { Reticulocyte distribution width (RDWr) }\end{array}$ & 1 & 57 \\
\hline & $\begin{array}{l}\text { Haemoglobin distribution width (HDW), eosinophils, Mean corpuscular volume of } \\
\text { reticulocytes) MCVr, Cell haemoglobin concentration mean of mature RBCs } \\
\text { (CHCMm), Cell haemoglobin concentration mean of reticulocytes (CHCMr), } \\
\text { RBC distribution width of mature erythrocytes (RDWm) }\end{array}$ & 2 & 56 \\
\hline & $\begin{array}{l}\text { Large unstained cells (LUC), Percentage of microcytic RBC (MICRO \%), Ratio } \\
\text { between the percentage of microcytic and hypochromic RBCs (\%MYCRO/\% } \\
\text { HYPO RATIO) }\end{array}$ & 3 & 55 \\
\hline & Cell haemoglobin concentration mean (CHCM) & 5 & 53 \\
\hline & Haemoglobin distribution width of reticulocytes (HDWr) & 8 & 50 \\
\hline & Percentage of hyperchromic RBCs (HYPER \%) & 11 & 47 \\
\hline \multirow[t]{4}{*}{52} & Albumin, urea & 1 & 51 \\
\hline & $\begin{array}{l}\text { Total protein, creatinine, Alanine aminotransferase (ALT), Aspartate } \\
\text { aminotransferase (AST) }\end{array}$ & 2 & 50 \\
\hline & Glucose & 4 & 48 \\
\hline & Alkaline phosphatase (ALP) & 7 & 45 \\
\hline \multirow[t]{4}{*}{45} & Cholesterol, Na, K, Creatine Kinase (CK), P, Fe & 1 & 44 \\
\hline & Triglycerides & 2 & 43 \\
\hline & Gamma-glutamyl transferase (GGT) & 3 & 42 \\
\hline & $\mathrm{Ca}$ & 4 & 41 \\
\hline
\end{tabular}

corpuscular volume (MCV), Mean corpuscular haemoglobin (MCH), Mean cell (MPC), Haemoglobin content of reticulocytes $(\mathrm{CHr}), \mathrm{CH}$ distribution width of fluorescence reticulocytes (L Retic \%), Number of low fluorescence reticulocyte (L Retic \#), Percentage of medium fluorescence reticulocytes (M Retic \%), Percentage of high fluorescence reticulocytes (H Retic \%), Number of high fluorescence (IRF-H), Immature reticulocyte fraction with medium/high fluorescence (IRF $\mathrm{M}+\mathrm{H}$ ) emoglobin distribution width (HDW), eosinophils, Mean corpuscular volume of reticulocytes) $\mathrm{MCVr}$, Cell haemoglobin concentration mean of mature RBCs (CHCMm), Cell haemoglobin concentration mean of reticulocytes (CHCMr), distribution width of mature erythrocytes (RDWm) between the percentage of microcytic and hypochromic RBCs (\%MYCRO/\%

Cell haemoglobin concentration mean (CHCM)

Haemoglobin distribution width of reticulocytes (HDWr)

Albumin, urea

Total protein, creatinine, Alanine aminotransferase (ALT), Aspartate

\section{ded}


Table 2. Haematological reference intervals for PLI established within this study. Data are reported according to the ASVCP guidelines (Friedrichs et al., 2012)

\begin{tabular}{|c|c|c|c|c|c|c|c|c|c|c|c|c|}
\hline Analyte & $\begin{array}{l}\text { Claimed } \\
\text { RI }\end{array}$ & $N$ & Mean & SD & Median & Min & Max & RI & $\begin{array}{c}\text { LRL } \\
(90 \% \mathrm{CI})\end{array}$ & $\begin{array}{c}\text { URL } \\
(90 \% \mathrm{CI})\end{array}$ & Dist & Meth \\
\hline HGB (g/L) & $120-180$ & 58 & 180 & 18 & 179 & 142 & 237 & $1 \mathrm{~S}$ & $\begin{array}{c}146(140- \\
153)\end{array}$ & $219(211-227)$ & $\begin{array}{c}P=0.893 \\
(\mathrm{G})\end{array}$ & RT \\
\hline $\mathrm{MCH}(\mathrm{pg})$ & $19-24$ & 58 & 23.7 & 0.8 & 23.7 & 21.5 & 25.3 & $N$ & $\begin{array}{c}22.0(21.7- \\
22.4)\end{array}$ & $\begin{array}{c}25.4(25.1- \\
25.8)\end{array}$ & $\begin{array}{c}P=0.754 \\
(\mathrm{G})\end{array}$ & RT \\
\hline $\begin{array}{r}\mathrm{MCHC} \\
(\mathrm{g} / \mathrm{L})\end{array}$ & $320-360$ & 58 & 371 & 10 & 370 & 351 & 406 & $3 \mathrm{~S}$ & $\begin{array}{c}351(351- \\
357)\end{array}$ & $403(385-406)$ & $\begin{array}{c}P=0.009 \\
(\mathrm{NG})\end{array}$ & NP \\
\hline $\begin{array}{r}\mathrm{CHCM} \\
(\mathrm{g} / \mathrm{L})\end{array}$ & $297-328$ & 53 & 361 & 13 & 359 & 333 & 404 & $4 \mathrm{~S}$ & $\begin{array}{c}336(333- \\
345)\end{array}$ & $403(383-404)$ & $\begin{array}{c}P=0.000 \\
(\mathrm{NG})\end{array}$ & NP \\
\hline $\mathrm{CH}$ (pg) & n.a. & 58 & 23.3 & 1.1 & 23.2 & 20.6 & 27.3 & $3 \mathrm{~S}$ & $\begin{array}{l}21.1(20.6- \\
21.9)\end{array}$ & $\begin{array}{c}26.7(25.0- \\
27.3)\end{array}$ & $\begin{array}{c}P=0.028 \\
(\mathrm{NG})\end{array}$ & NP \\
\hline $\begin{array}{l}\text { HDW } \\
\qquad(\mathrm{g} / \mathrm{dL})\end{array}$ & $1.24-1.82$ & 56 & 2.1 & 0.5 & 1.9 & 1.5 & 3.5 & $6 S$ & $\begin{array}{c}1.5(1.5- \\
1.6)\end{array}$ & $3.5(3.3-3.5)$ & $\begin{array}{c}P=0.000 \\
(\mathrm{NG})\end{array}$ & NP \\
\hline $\begin{array}{l}\text { RETIC } \\
\qquad\left(10^{6} / \mathrm{L}\right)\end{array}$ & $0.0-60.0$ & 58 & 50.4 & 32.3 & 41.1 & 8.8 & 117.6 & $N$ & $\begin{array}{c}9.5(8.9- \\
12.8)\end{array}$ & $\begin{array}{c}117.3(112.2- \\
117.6)\end{array}$ & $\begin{array}{c}P=0.276 \\
(G)\end{array}$ & RT \\
\hline $\begin{array}{l}\mathrm{CHCMr} \\
(\mathrm{g} / \mathrm{L})\end{array}$ & $262-281$ & 56 & 307 & 11 & 306 & 279 & 335 & $4 \mathrm{~S}$ & $\begin{array}{c}280(279- \\
293)\end{array}$ & $333(326-335)$ & $\begin{array}{c}P=0.008 \\
(\mathrm{NG})\end{array}$ & NP \\
\hline $\mathrm{CHr}(\mathrm{pg})$ & $22.3-27.9$ & 58 & 26.8 & 0.9 & 27.0 & 23.8 & 28.1 & $3 \mathrm{~S}$ & $\begin{array}{c}24.0(23.8- \\
25.1)\end{array}$ & $\begin{array}{l}28.1(27.9- \\
28.1)\end{array}$ & $\begin{array}{c}P=0.002 \\
(\mathrm{NG})\end{array}$ & NP \\
\hline RDWr & $11-19.54$ & 57 & 13.8 & 4.1 & 12.6 & 10.2 & 26.5 & $4 \mathrm{~S}$ & $\begin{array}{c}10.2(10.2- \\
10.5)\end{array}$ & $\begin{array}{c}26.0(22.6- \\
26.5)\end{array}$ & $\begin{array}{c}P=0.000 \\
(\mathrm{NG})\end{array}$ & NP \\
\hline $\mathrm{L}$ retic (\%) & $\begin{array}{c}64.83- \\
91.30\end{array}$ & 58 & 65.9 & 10.2 & 65.7 & 46.7 & 91.9 & $N$ & $\begin{array}{c}46.9(46.7- \\
50.0)\end{array}$ & $\begin{array}{c}89.9(80.1- \\
91.9)\end{array}$ & $\begin{array}{c}P=0.910 \\
(G)\end{array}$ & NP \\
\hline $\mathrm{H}$ retic (\%) & $\begin{array}{l}4.31- \\
10.04\end{array}$ & 58 & 14.9 & 7.2 & 13.8 & 2.0 & 34.3 & $N$ & $\begin{array}{c}2.6(2.0- \\
6.5)\end{array}$ & $\begin{array}{c}32.8(26.2- \\
34.3)\end{array}$ & $\begin{array}{c}P=0.010 \\
(\mathrm{NG})\end{array}$ & NP \\
\hline $\begin{array}{l}\text { H retic } \\
\qquad\left(\times 10^{12} / \mathrm{L}\right)\end{array}$ & $5-75$ & 58 & 6.1 & 6.7 & 2.7 & 0.2 & 22.4 & $N$ & $\begin{array}{c}0.2(0.2- \\
1.1)\end{array}$ & $\begin{array}{c}22.3(17.5- \\
22.4)\end{array}$ & $\begin{array}{c}P=0.017 \\
(\mathrm{NG})\end{array}$ & NP \\
\hline IRF-H (\%) & n. a. & 58 & 14.9 & 7.2 & 13.8 & 2.0 & 34.3 & $N$ & $\begin{array}{c}2.6(0.1- \\
3.5)\end{array}$ & $\begin{array}{c}32.5(25.4- \\
36.3)\end{array}$ & $\begin{array}{c}P=0.010 \\
(\mathrm{NG})\end{array}$ & NP \\
\hline IRF $\mathrm{M}+\mathrm{H}$ & n. a. & 58 & 34.1 & 10.2 & 34.3 & 8.1 & 53.3 & $N$ & $\begin{array}{c}10.1(8.1- \\
17.7)\end{array}$ & $\begin{array}{c}53.1(49.8- \\
53.3)\end{array}$ & $\begin{array}{c}P=0.903 \\
(\mathrm{G})\end{array}$ & $\mathrm{R}$ \\
\hline $\begin{array}{l}\text { WBC } \\
\left(10^{9} / \mathrm{L}\right)\end{array}$ & $6.0-19.5$ & 58 & 7.3 & 2.2 & 7.0 & 3.8 & 12.8 & $N$ & $\begin{array}{c}4.2\left(3.8^{-}\right. \\
4.5)\end{array}$ & $\begin{array}{c}12.5(11.0- \\
14.0)\end{array}$ & $\begin{array}{c}P=0.001 \\
(\mathrm{NG})\end{array}$ & RT \\
\hline LUC $\left(10^{9} / \mathrm{L}\right)$ & $0.55-1.71$ & 55 & 0.5 & 0.5 & 0.3 & 0.1 & 1.6 & $5 S$ & $\begin{array}{c}0.1(0.1- \\
0.1)\end{array}$ & $1.6(1.4-1.6)$ & $\begin{array}{c}P=0.000 \\
(\mathrm{NG})\end{array}$ & NP \\
\hline $\operatorname{MPV}\left(\mathrm{m}^{3}\right)$ & $8.5-13.5$ & 58 & 8.6 & 1.0 & 8.5 & 6.6 & 11.5 & $2 \mathrm{~S}$ & $\begin{array}{c}6.8(6.6- \\
7.3)\end{array}$ & $\begin{array}{c}11.3(10.5- \\
11.5)\end{array}$ & $\begin{array}{c}P=0.055 \\
(\mathrm{NG})\end{array}$ & NP \\
\hline
\end{tabular}

$N=$ number of valid observations; $\mathrm{SD}=$ standard deviation; Out = outliers; RI = reference interval; $\mathrm{LRL}=$ lower reference limit; $\mathrm{URL}=$ upper reference limit; Dist = distribution; Meth = method; $(S)=$ number of suspected outliers; $(\mathrm{R})=$ number of far outliers that were identified and removed; $\mathrm{G}=$ Gaussian; NG = non-Gaussian; NP = non-parametric; $\mathrm{R}=$ robust method; RT = robust method after boxcox transformation.

The bold values signify the reference intervals established within this study for PLI.

\section{Partitioning of Rls}

The caseload included 27 females, 6 spayed females, 23 males and 2 neutered males. However, only results from males and females were compared to each other, because the number of spayed females and neutered males was too low to allow a reliable statistical analysis. Compared with females, male PLIs had higher MCV $(P=0.007)$ and GGT $(P=0.003)$ and lower CHCM $(\mathrm{P}=0.014), \operatorname{RDWr}(P=0.009), \operatorname{HDWr}(P=$ $0.002), \mathrm{Na}(P=0.000), \mathrm{K}(P=0.020)$ and $\mathrm{CK}(P=0.003)$.

The age range was 8 months-13 years (mean: $4.31 \pm$ 3.35; median: 4 years). Linear regression analysis showed a significant increase with age for $\operatorname{MCV}(P=0.021)$, platelets (PLT) $(P<0.001)$, reticulocyte number $(P=0.057)$, MCVr
$(P=0.004)$, H-Retic\# $(P=0.045)$ and total protein $(P=$ 0.045). Conversely, MCHC $(\mathrm{P}<0.001)$, CHCM $(P<0.011)$, CHCMr $(P=0.000)$, lymphocytes $(P=0.002)$, basophils $(P$ $=0.054), \operatorname{RDWr}(P=0.042), \operatorname{HDWr}(P=0.027)$ and urea $(P=0.031)$ significantly decreased with age. When age was arbitrarily divided into three classes, compared with the other groups, dogs older than 7 years had significantly higher $\operatorname{MCV}(P=0.040)$ and PLT $(P<0.001)$, and significantly lower MCHC $(P=0.001)$, lymphocytes $(P=0.026)$ and $\mathrm{CHCMr}(P=0.007)$, while dogs aged 2-7 years had higher $\operatorname{MCVr}(\mathrm{P}=0.007)$.

Racing dogs $(n=11)$ had lower HCT $(P=0.047)$, RDW $(P=0.015), \operatorname{MCVm}(P=0.024)$ and $\operatorname{MCVr}(P=0.009)$, and higher $\operatorname{MCHC}(P=0.030), \operatorname{CHCMr}(P=0.002)$, 


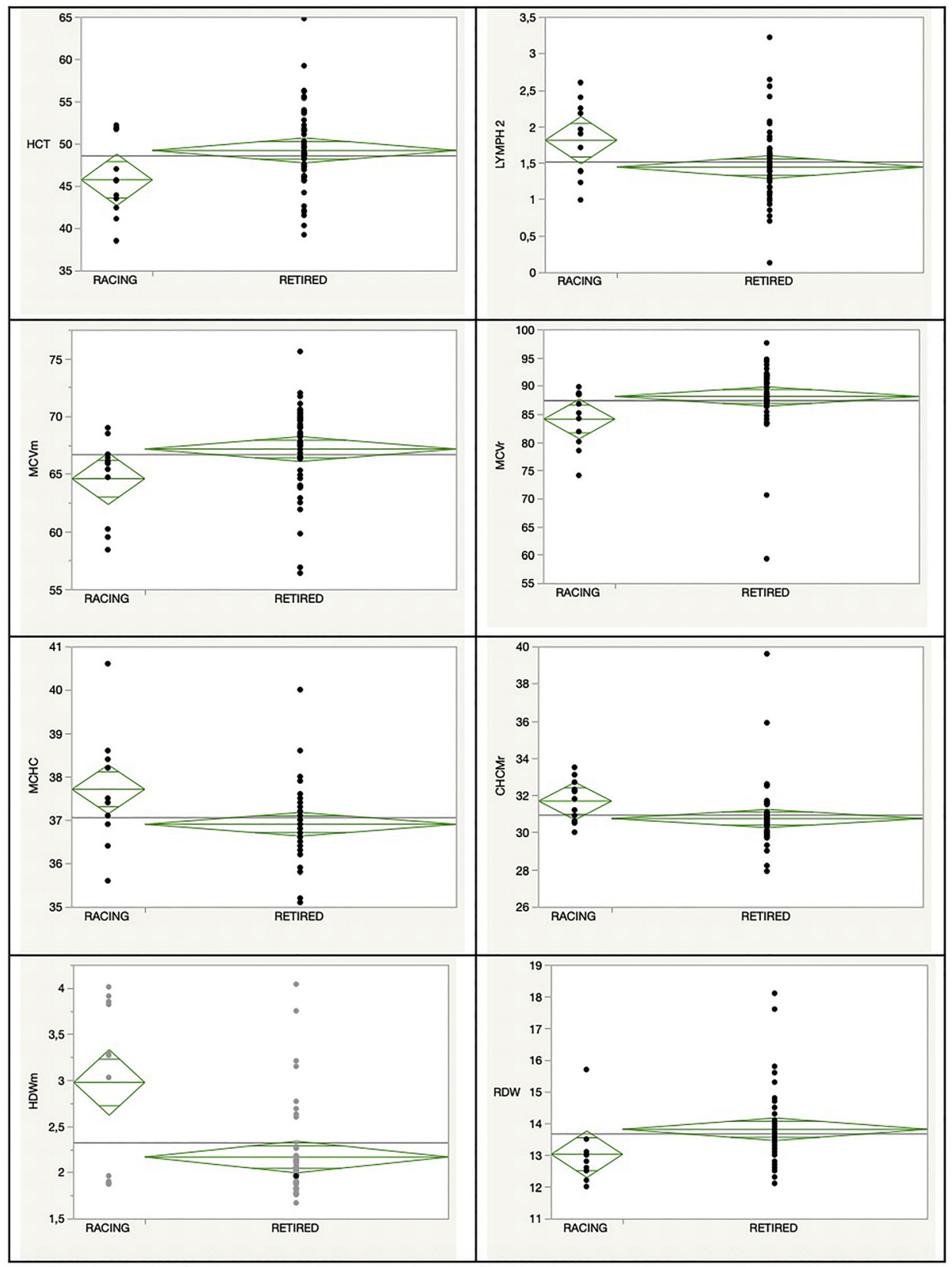

Figure 1. Significant differences between racing and retired PLI. Racing dogs had lower values for HCT (A), RDW (B), MCVm (C) and $\operatorname{MCVr}(\mathrm{D})$, and higher values for MCHC (E), CHCMr (F), HDWm (G) and lymphocytes (H)

HDWm $(P=0.030)$ and lymphocytes $(P=0.046)$ than retired dogs $(n=47)$ (Fig. 1$)$.

\section{DISCUSSION}

This study evidenced some haematological or biochemical peculiarities in PLIs. The breeders enrolled in this study did not use dietary or management practices potentially influencing the laboratory results. Therefore, the observed peculiarities are most likely interpretable as breed-specific. Alternatively, some of these peculiarities might depend on the comparison with RIs published in textbooks rather than with RIs generated in-house from a reference population (Kaneko et al., 2008; Kjelgaard-Hansen and Lundorff, 2010). Only for ADVIA-specific parameters regarding red blood cells (RBCs) or reticulocytes, that were not published in textbooks, data were compared with RIs reported in an article that used the same methodology as that employed in this study (Moritz et al., 2004). Likewise, we preferred to compare routine haematological parameters with those reported in the Schalm's textbook (Rizzi et al., 2010), since the data reported by Moritz et al. (2004) are based on a reference population numerically lower than that of our study and not generated using the recent guidelines (Geffré et al., 2009; Friedrichs et al., 2012). Other studies investigated ADVIA 
Table 3. Biochemical reference intervals for PLI established within this study. Data are reported according to the ASVCP guidelines (Friedrichs et al., 2012)

\begin{tabular}{|c|c|c|c|c|c|c|c|c|c|c|c|c|}
\hline Analyte & $\begin{array}{l}\text { Claimed } \\
\text { RI }\end{array}$ & $N$ & Mean & SD & Median & Min & Max & RI & $\begin{array}{l}\text { LRL ( } 90 \% \\
\quad \text { CI) }\end{array}$ & $\begin{array}{l}\text { URL }(90 \% \\
\text { CI) }\end{array}$ & Dist & Meth \\
\hline $\begin{array}{l}\text { Total protein } \\
(\mathrm{g} / \mathrm{L})\end{array}$ & $54-71$ & 50 & 63 & 8 & 61 & 47 & 80 & $1 \mathrm{~S}$ & $48(47-54)$ & $80(78-81)$ & $\begin{array}{c}P=0.008 \\
(\mathrm{NG})\end{array}$ & NP \\
\hline $\begin{array}{l}\text { Albumin (g/ } \\
\text { L) }\end{array}$ & $23-33$ & 51 & 36 & 4 & 36 & 29 & 50 & $2 \mathrm{~S}$ & $29(29-32)$ & $48(42-50)$ & $\begin{array}{c}P=0.002 \\
(\mathrm{NG})\end{array}$ & NP \\
\hline $\begin{array}{l}\text { Cholesterol } \\
\quad(\mathrm{mmol} / \mathrm{L})\end{array}$ & $3.5-7$ & 44 & 5.1 & 1.3 & 4.8 & 2.7 & 7.8 & $N$ & $2.3(1.9-2.9)$ & $7.8(7.1-8.4)$ & $\begin{array}{c}P=0.251 \\
(G)\end{array}$ & RT \\
\hline $\mathrm{Na}(\mathrm{mmol} / \mathrm{L})$ & $141-152$ & 44 & 156.8 & 6.9 & 156.4 & 146.3 & 171.6 & $N$ & $\begin{array}{c}142.4(140.0- \\
145.5)\end{array}$ & $\begin{array}{c}170.4(166.6- \\
173.8)\end{array}$ & $\begin{array}{c}P=0.503 \\
(\mathrm{G})\end{array}$ & $\mathrm{R}$ \\
\hline $\mathrm{Ca}(\mathrm{mmol} / \mathrm{L})$ & $9-11.3$ & 41 & 3.0 & 0.4 & 3 & 2.2 & 4.2 & $1 \mathrm{~S}$ & $2.3(2.2-2.4)$ & $4.1(3.8-4.5)$ & $\begin{array}{c}P=0.362 \\
(\mathrm{G})\end{array}$ & NP \\
\hline Iron $(\mu \mathrm{mol} / \mathrm{L})$ & $16.1-35.8$ & 44 & 40.7 & 11.7 & 40.4 & 13.6 & 65.1 & $N$ & $\begin{array}{c}18.0(13.9- \\
22.3)\end{array}$ & $\begin{array}{c}65.3(57.5- \\
71.9)\end{array}$ & $\begin{array}{c}P=0.290 \\
(G)\end{array}$ & $\mathrm{RT}$ \\
\hline
\end{tabular}

$N=$ number of valid observations; SD = standard deviation; Out = outliers; RI = reference interval; LRL $=$ lower reference limit; URL $=$ upper reference limit; Dist $=$ distribution; Meth = method; $(S)=$ number of suspected outliers; $(\mathrm{R})=$ number of far outliers that were identified and removed; $\mathrm{G}=$ Gaussian; NG = non-Gaussian; NP = non-parametric; $\mathrm{R}=$ robust method; RT = robust method after boxcox transformation.

The bold values signify the reference intervals established within this study for PLI.

parameters in selected storage or disease conditions (Furlanello et al., 2006) but data were expressed as mean \pm SD or min-max ranges and therefore not suitable for the comparison of RIs (Table 3).

Another limitation of this study is the low caseload. However, this study includes $20 \%$ of PLIs registered at the National Agency of the Italian Cynophily (ENCI). In addition, according to the recommendations of recent guidelines we applied strict inclusion criteria and we excluded far outliers, thus further reducing the number of valid data. Far outliers were frequently recorded for ADVIA parameters of minor clinical relevance (e.g. HDWr, HYPER\%) that had wide RIs also in a previous study (Moritz et al., 2004), likely due to a high individual and analytical variability for eosinophils, probably due to imprecisions in 'grey eosinophil' counts (Giori et al., 2011), and for some biochemical analytes, likely due to pre-analytical artefacts (e.g. glucose) or to possible analytical errors, that may have induced increases of ALP, GGT or Ca in dogs without signs of cholestasis or of altered bone metabolism.

The method used in this study to validate preexisting RIs has some limitation: for example, if all the observations fall within pre-existing RIs, suggesting that a narrower RI would better describe the study population, preexisting RIs are validated. Nevertheless, although other statistical approaches are mentioned in the CLSI guidelines, the approach followed in this study is widely used in veterinary medicine and is recommended by the ASVCP guidelines (Friedrichs et al., 2012). This approach rejected many preexisting haematological and biochemical RIs. Although for some parameters (e.g. cholesterol, MPV) this may reflect the limitation cited above, in most cases the differences compared with published RIs were already recorded in Greyhounds (Fayos et al., 2005; Campora et al., 2011a; Zaldívar-López et al., 2011), suggesting that these are real breed-specific peculiarities of sighthounds. For example, the high $\mathrm{Hb}$ and $\mathrm{MCHC}$ are considered adaptations to increase the oxygen delivery to tissues (Shiel et al., 2007), and the high $\mathrm{MCH}, \mathrm{CHCM}$ and serum iron may indicate a more efficient erythroid metabolism as suspected in Greyhounds (Caro et al., 2013). Theoretically, also the high reticulocyte count may be an adaptive response. However, this may depend on the high analytical sensitivity of laser-based analysers rather than on a true reticulocytosis (Moritz et al., 2004; Tvedten and Moritz, 2010). This hypothesis is confirmed by a recent report on Greyhounds in which reticulocyte counts increased only after racing, possibly due to splenic contraction (Horvath et al., 2014).

Other similarities with Greyhounds are the lower RIs for total WBC counts and the higher RI for sodium (Shiel et al., 2007; Zaldívar-López et al., 2011). As regards WBCs, however, the low neutrophil count recorded in Greyhounds was not found in PLI in which the RI for LUCs was lower than that reported in other studies (Moritz et al., 2004). This cell population, however, is clinically irrelevant, except in a few cases (Moritz and Becker, 2010).

Some discrepancies with Greyhounds, interpretable as PLI-specific peculiarities, were also found: serum calcium, that is low in Greyhounds, was higher than the published RIs for PLIs. Similarly, Greyhounds have a lower total protein concentration, mostly due to a decreased serum concentration of globulins and acute phase proteins (Zaldívar-López et al., 2011), while PLIs had a wider RI for total proteins and a higher RI for albumin (Couto et al., 2009). These differences are too slight to affect any clinical decisions and are probably breed peculiarities. It is otherwise hard to explain this increase in healthy dogs without any sign of dehydration and/or in dogs not receiving corticosteroid supplementation. Furthermore, the higher RI for albumin could be the explanation for the higher level of calcaemia detected (due to increased protein binding) (Stockham and Scott, 2008). Additionally, some peculiarities 
of Greyhounds such as increased creatinine, ALT and AST, were not found in PLIs. In a previous study, PLI had a significantly higher activity of liver enzymes compared with other sighthounds; on the other hand, normal serum creatinine had already been observed both in PLI and Saluki in the same comparative study (Uhrikova et al., 2013). Finally, the higher ALT, AST and creatinine of Greyhounds may depend on their larger muscle mass compared with PLIs.

Partitioning according to sex, age and aptitude revealed differences that in most cases (e.g. erythroid parameters, GGT, K or CK recorded in males and females) were statistically significant but likely not clinically relevant, since the results of each subgroup were within the pre-existing RIs or only slightly different from them.

The lack of significant differences among biochemical analytes generally affected by age (e.g. ALP, total proteins) may depend on the fact that very young animals were not included in the study. Similarly, age-related changes in haematology usually occur at 9-10 months of age, when $\mathrm{Hct}, \mathrm{Hb}$ concentration and $\mathrm{RBC}$ count increase (Shiel et al., 2007). The most significant age-related changes in our caseload were a trend to macrocytosis and hypochromasia both in mature RBCs and in reticulocytes, consistent with what was reported in people (Mahmoud et al., 1996).

In Greyhounds, several haematological or biochemical changes were found after sprint exercise (Ilkiw et al., 1989; Toll et al., 1995) or during the racing season (Lassen et al., 1986). None of these changes was detected in PLIs, except for a moderate increase of lymphocytes. However, a trend to microcytosis and increased MCHC or CHCM was found both in mature RBCs and in reticulocytes.

Reduced iron status in athletes has been documented in racing sled dogs (Kenyon et al., 2011). Although we are aware of the fact that our PLI are subjected to a different type of physical effort (training sessions during the training season), it is difficult to justify the high serum iron recorded in the present study, which contrasts with previous reports.

The low Hct in racing compared with retired PLIs also contrasts with the previous reports on Greyhounds (Zaldívar-López et al., 2011). Short maximal exercise in dogs could lead to metabolic acidosis with respiratory compensation and increased plasma $\mathrm{Na}, \mathrm{K}$ and proteins (Ilkiw et al., 1989). This was not found in this study in which, however, the samples were not collected after race but during the racing season, when it has been previously demonstrated that haematological parameters do not change significantly (Lassen et al., 1986).

In humans, the increased plasma volume due to an increased production of aldosterone and osmotically active plasma proteins may lead to a relative decrease of HCT, defined as 'sports anaemia'.

In conclusion, this study has demonstrated that most of the RIs published in veterinary textbooks cannot be validated for Italian Greyhounds (PLIs). However, only some of these differences can be interpreted as breed-specific peculiarities, likely due to the adaptation of this breed to racing aptitude.
Rather, the RBCs of PLIs seem to have a more intense haemoglobin synthesis. Interestingly, this mechanism of adaptation seems to differ from that hypothesised in Greyhounds, in which, in association with the increased $\mathrm{Hb}$ and MCHC, also an increased RBC count and Hct level are reported. Additional peculiarities of PLIs include a WBC count lower than in other breeds, in agreement with what was reported in Greyhounds, wider protein and albumin intervals, and a serum calcium level which, unlike in other sighthounds, is higher than the published RIs, probably due to the higher protein binding.

\section{ACKNOWLEDGEMENTS}

The authors are grateful to Dr. A. Anselmi (Centro Medico Veterinario Castano Primo, Milan, Italy) for his help in introducing us to the 'PLI world'.

\section{REFERENCES}

Campora, C., Freeman, K. P., Lewis, F. I., Gibson, G., Sacchini, F. and Sanchez-Vazquez, M. J. (2011a): Determination of haematological reference intervals in healthy adult Greyhounds. J. Small Anim. Pract. 52, 301-309.

Campora, C., Freeman, K. P., Serra, M. and Sacchini, F. (2011b): Reference intervals for Greyhounds and Lurchers using the Sysmex XT-2000iV hematology analyzer. Vet. Clin. Pathol. 40, 467-474.

Caro, J. T., Marín, L. M., Iazbik, M. C., Zaldivar-López, S., Borghese, H., Couto, C. G. (2013): Markers of iron metabolism in retired racing Greyhounds with and without osteosarcoma. Vet. Clin. Pathol. 42, 360-363.

CLSI (2010): Defining, Establishing and Verifying Reference Intervals in the Clinical Laboratory; Approved Guideline. Third ed. CLSI document EP28-A3c. Clinical and Laboratory Standards Institute, Wayne, PA.

Couto, C. G., Cerón, J. J., Parra, M. D., Martìnez-Subiela, S. and Iazbik, M. C. (2009): Acute phase protein concentrations in retired racing Greyhounds. Vet. Clin. Pathol. 38, 219-223.

Fayos, M., Couto, C. G., Iazbik, M. C. and Wellman, M. L. (2005): Serum protein electrophoresis in retired racing Greyhounds. Vet. Clin. Pathol. 34, 397-400.

Friedrichs, K. R., Harr, K. E., Freeman, K. P., Szladovits, B., Walton, R. M., Barnhart, K. F., Blanco-Chavez, J. and American Society for Veterinary Clinical Pathology (2012): ASVCP reference interval guidelines: determination of de novo reference intervals in veterinary species and other related topics. Vet. Clin. Pathol. 41, 441-453.

Furlanello, T., Tasca, S., Caldin, M., Carli, E., Patron, C., Tranquillo, M., Lubas, G. and Solano-Gallego, L. (2006): Artifactual changes in canine blood following storage, detected using the ADVIA 120 hematology analyzer. Vet. Clin. Pathol. 35, 42-46.

Geffré, A., Concordet, D., Braun, J. P. and Trumel, C. (2011): Reference value advisor: a new freeware set of macroinstructions to calculate reference intervals with Microsoft Excel. Vet. Clin. Pathol. 40, 107-112. 
Geffré, A., Friedrichs, K., Harr, K., Concordet, D., Trumel, C. and Braun, J. P. (2009): Reference values: a review. Vet. Clin. Pathol. 38, 288-298.

Giori, L., Gironi, S., Scarpa, P., Anselmi, A., Gualtieri, M. and Paltrinieri, S. (2011): Grey eosinophils in sighthounds: frequency in 3 breeds and comparison of eosinophil counts determined manually and with 2 hematology analyzers. Vet. Clin. Pathol. 40, 475-483.

Horn, P. S. and Pesce, A. J. (2002): Effect of ethnicity on reference intervals. Clin. Chem. 48, 1802-1804.

Horvath, S. J., Couto, C. G., Yant, K., Kontur, K., Bohenko, L., Iazbik, M. C., Marin, L. M., Hudson, D., Chase, J., Frye, M. and Denicola, D. B. (2014): Effects of racing on reticulocyte concentrations in Greyhounds. Vet. Clin. Pathol. 43, 15-23.

Ilkiw, J. E., Davis, P. E. and Church, D. B. (1989): Hematologic, biochemical, blood-gas, and acid-base values in greyhounds before and after exercise. Am. J. Vet. Res. 50, 583-586.

Kaneko, J. J., Harvey, J. W. and Bruss, M. L. (2008): Appendix IX. In: Kaneko, J. J., Harvey, J. W. and Bruss, M. L. (eds) Clinical Biochemistry of Domestic Animals. Sixth ed. Academic Press, San Diego, CA. pp. 898-899.

Kenyon, C. L., Basaraba, R. J. and Bohn, A. A. (2011): Influence of endurance exercise on serum concentrations of iron and acute phase proteins in racing sled dogs. J. Am. Vet. Med. Assoc. 239, 1201-1210.

Kjelgaard-Hansen, M. and Lundorff, J. A. (2010): Reference intervals. In: Weiss, D. J. and Wardrop, K. J. (eds) Schalm's Veterinary Hematology. Sixth ed. Wiley-Blackwell Publishing, Ames, IA. pp. 1034-1038.

Lassen, E. D., Craig, A. M. and Blythe, L. L. (1986): Effects of racing on hematologic and serum biochemical values in Greyhounds. J. Am. Vet. Med. Assoc. 188, 1299-1303.

Mahmoud, M. Y., Lugon, M. and Anderson, C. C. (1996): Unexplained macrocytosis in elderly patients. Age Ageing 25, 310-312.

Moritz, A. and Becker, M. (2010): Automated hematology systems. In: Weiss, D. J. and Wardrop, K. J. (eds) Schalm's Veterinary Hematology. Sixth ed. Wiley-Blackwell Publishing, Ames, IA. pp. 1054-1066.
Moritz, A., Fickenscher, Y. and Meyer, K. (2004): Canine and feline hematology reference values for the ADVIA 120 hematology system. Vet. Clin. Pathol. 33, 32-38.

Nielsen, L., Kjelgaard-Hansen, M., Jensen, A. L. and Kristensen, A. T. (2010): Breed-specific variation of hematologic and biochemical analytes in healthy adult Bernese Mountain dogs. Vet. Clin. Pathol. 39, 20-28.

Paltrinieri, S., Ibba, F. and Rossi, G. (2014): Haematological and biochemical reference intervals of four feline breeds. J. Feline Med. Surg. 16, 125-136.

Rizzi, T. E., Meinkoth, J. H. and Clinkenbeard, K. D. (2010): Normal hematology of the dog. In: Weiss, D. J. and Wardrop, K. J. (eds) Schalm's Veterinary Hematology. Sixth ed. WileyBlackwell Publishing, Ames, IA. pp. 799-810.

Ruggerone, B., Giraldi, M., Paltrinieri, S. and Scarpa, P. (2018): Hematologic and biochemical reference intervals in Shetland Sheepdog. Vet. Clin. Pathol. 47, 617-624.

Shiel, R. E., Brennan, S. F., O’Rourke, L. G., McCullough, M. and Mooney, C. T. (2007): Hematologic values in young pretraining healthy Greyhounds. Vet. Clin. Pathol. 36, 274-277.

Stockham, S. L. and Scott, M. A. (2008): Calcium, phosphorus, magnesium and their regulatory hormones. In: Fundamentals of Veterinary Clinical Pathology. Second ed. Blackwell Publishing, Ames, IA. pp. 593-602.

Toll, P. W., Gaehtgens, P., Neuhaus, D., Pieschi, R. L. and Fedde, M. R. (1995): Fluid, electrolyte, and packed cell volume shifts in racing greyhounds. Am. J. Vet. Res. 56, 227-232.

Tvedten, H. and Moritz, A. (2010): Reticulocyte and Heinz body staining and enumeration. In: Weiss, D. J. and Wardrop, K. J. (eds) Schalm's Veterinary Hematology. Sixth ed. WileyBlackwell Publishing, Ames, IA. pp. 1067-1073.

Uhrikova, I., Lacnakova, A., Tandlerova, K., Kucharova, V., Rehakova, K., Janova, E. and Doubek, J. (2013): Haematological and biochemical variations among eight sighthound breeds. Aust. Vet. J. 91, 452-459.

Zaldívar-López, S., Marín, L. M., Iazbik, M. C., Westendorf-Stingle, N., Hensley, S. and Couto, C. G. (2011): Clinical pathology of Greyhounds and other sighthounds. Vet. Clin. Pathol. 40, 414-425. 